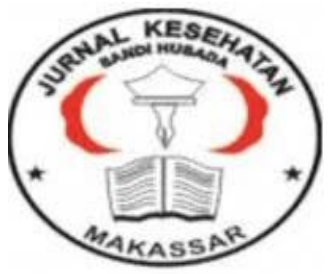

Jurnal Ilmiah Kesehatan Sandi Husada

hhttps://akper-sandikarsa.e-journal.id/JIKSH

Volume 9, Nomor 2, Desember 2020, pp773-778

p-ISSN: 2354-6093 dan e-ISSN: 2654-4563

DOI: $10.35816 /$ jiskh.v10i2.402

\title{
Pengaruh Personal Hygiene Terhadap Kejadian Penyakit Skabies
}

The Personal Hygiene Impact on the Incidence of Scabies

Muhammad Panji Marga

Pendidikan Dokter, Fakultas Kedokteran Universitas Lampung

Artikel info

Artikel history:

Received; Juli 2020

Revised: Agustus 2020

Accepted; Agustus 2020

\begin{abstract}
Abstrak
Latar Belakang: Skabies merupakan penyakit kulit yang disebabkan oleh infestasi dan sensitisasi terhadap tungau Sarcoptes scabiei. hominis yang terjadi pada komunitas, kelompok, atau keluarga yang tinggal dihunian padat, ekonomi rendah, dan pengetahuan rendah. Pemeliharaan personal hygiene sangat menentukan status kesehatan, dimana individu secara sadar dan atas inisiatif pribadi menjaga kesehatan dan mencegah terjadinya penyakit. Tujuan: Mengetahui lebih lanjut tentang pengaruh personal hygiene terhadap kejadian penyakit skabies. Metode: Menggunakan studi literatur dari jurnal baik nasional maupun internasioanl dengan cara meringkas topik pembahasan dan membandingkan hasil yang disajikan didalam artikel. Hasil: Ada pengaruh yang bermakna antara kebiasaan personal hygiene dengan kejadian penyakit skabies. Kesimpulan: Terdapat hubungan signifikan antara personal hygiene seseorang dengan kejadian penyakit skabies.
\end{abstract}

\section{Abstract}

Background: Scabies is a skin disease caused by infestation and sensitization of the Sarcoptes Scabiei v. Hominis mite that occurs in communities, groups, or families living in dense, low economy, and low knowledge. Maintenance of personal hygiene strongly determines the health status, where the individual consciously and on the personal initiative to maintain health dan prevent disease. Objective: Know more about the personal effect of hygiene on the incidence of scabies. Methods: Using literature studies from both national and international journals by summarizing the topic of discussion and comparing the results presented in the article. Results: There is a meaningful influence between personal hygiene habits and the incidence of scabies. Conclusion: There is a significant connection between a person's personal hygiene with the incidence of scabies. 


\begin{tabular}{lr}
\hline Keywords: & $\begin{array}{r}\text { Coresponden author: } \\
\text { Personal Hygiene; }\end{array}$ \\
Scabies; & Email: panjimarga797@gmail.com \\
& artikel dengan \\
& akses terbuka dibawah lisensi CC BY 4.0 \\
\hline
\end{tabular}

\section{Pendahuluan}

Skabies merupakan penyakit kulit menular yang di akibatkan oleh infestasi tungau Sarcoptes scabiei var hominis yang membentuk terowongan pada lapisan pejamu. S. Scabiei tergolong penyakit signifikan bagi kesehatan masyarakat karena termasuk parasit obligat pada manusia. Skabies menjadi masalah yang umum di dunia, karena hampir semua golongan usia, ras, dan kelompok sosial ekonomi. (Ariza et al., 2013). Menurut WHO (World Health Organization) terdapat sekitar 300 juta kasus skabies di dunia setiap tahunnya. Insiden skabies di Indonesia masih sangat tinggi, terendah di Sulawesi Selatan dan tertinggi di Jawa Barat. Prevalensi skabies di puskesmas seluruh Indonesia pada tahun 2008 adalah 5,6\%-12,95\% dan skabies menduduki urutan ketiga dari 12 penyakit kulit tersering (Depkes RI, 2008). Di Indonesia pada tahun 2011 didapatkan jumlah penderita skabies sebesar 6.915.135 (2,9\%) dari jumlah penduduk 238.452 .952 jiwa dan jumlah ini mengalami peningkatan pada tahun 2012 diperkirakan sebesar 3,6\% dari jumlah penduduk (Depkes RI, 2012).

Penularan terjadi akibat kontak langsung dengan kulit pasien atau tidak langsung dengan benda yang tekontaminasi oleh tungau. Penyebab skabies antara lain disebabkan oleh rendahnya faktor sosial ekonomi, kebersihan yang buruk seperti mandi, pemakaian handuk secara bersamaan dan jarang diganti, frekuensi mengganti pakaian yang jarang dan melakukan hubungan seksual (Frenki, 2011). Personal hygiene atau biasa disebut dengan kebersihan diri adalah upaya untuk memelihara hidup sehat meliputi kehidupan bermasyarakat dan kebersihan beraktifitas. Personal Hygiene bisa disebut juga perawatan diri untuk mempertahankan kesehatan, baik secara fisik maupun psikologi. Kebersihan merupakan salah satu perilaku untuk mencegah timbulnya penyakit. Personal Hygiene dipengaruhi beberapa faktor diantaranya nilai sosial individu dan budaya, terutama pengetahuan dan persepsi mengenai kebersihan diri (Desmawati, 2015).

Pengetahuan seseorang dapat mendukung terhindar dari suatu penyakit, terutama penyakit menular. Angka kejadian penyakit skabies meningkat pada kelompok masyarakat yang hidup dengan kondisi kebersihan diri dan lingkungan di bawah standar (Rohmawati, 2010). Hal ini disebabkan kurangnya pengetahuan masyarakat tentang skabies, faktor penyebab, cara penyebaran, hingga pencegahan (Audhah et al, 2012). Pada kelompok masyarakat yang mempunyai pengetahuan yang rendah terhadap perilaku hidup bersih dan sehat mereka mempunyai resiko terkena penyakit skabies 2,34 kali dibandingkan kelompok masyarakat yang mempunyai pengetahuan baik tentang perilaku hidup bersih dan sehat (Rohmawati, 2010). Berdasarkan uraian di atas dapat disimpulkan bahwa perilaku kesehatan dan pengetahuan terhadap penyakit skabies dapat memperngaruhi kejadian skabies. Dengan demikian, peningkatan pengetahuan dan promosi kesehatan terhadap perilaku kesehatan, pengetahuan, dan juga dapat memberi pengaruh terhadap penurunan kejadian skabies. Promosi kesehatan merupakan salah satu intervensi untuk meningkatkan kualitas pengetahuan dan personal hygiene seseorang. 


\section{Metode}

Metode yang digunakan adalah menggunakan studi literatur dari berbagai jurnal internasional maupun nasional, metode ini digunakan untuk meringkas suatu topik yang berfungsi agar meningkatkan pemahaman terkini. Studi literatur menyajikan ulang materi yang diterbitkan sebelumnya, dan melaporkan fakta atau analisis baru dan tinjauan literatur memberikan ringkasan berupa publikasi terbaik dan paling relevan kemudian membandingkan hasil tersebut dalam artikel. Peneliti menggunakan studi literatur dari 20 jurnal yang terdiri dari jurnal nasional dan internasional yang didapatkan melalui google schoolar dengan membuka website, kemudian peneliti menuliskan kata kunci sesuai dengan MESH (Medical Subject Heading).

\section{Hasil Dan Pembahasan}

Skabies adalah suatu infestasi pada kulit manusia yang disebabkan oleh penetrasi parasit obligat yaitu S. scabiei var hominis ke dalam epidermis (Badri M, 2008). Dampak yang ditimbulkan akibat skabies karena masalah personal hygiene yang pertama adalah dampak fisik, yaitu gangguan fisik kesehatan yang diakibatkan seseorang karena tidak terpeliharanya kebersihan diri dengan baik. Gangguan yang sering terjadi adalah gangguan integritas kulit, gangguan membran mukosa mulut, infeksi pada mata dan gangguan fisik pada kuku. Gangguan kedua tergolong dampak psikososial, yaitu seperti masalah sosial yang berhubungan dengan personal hygiene seperti gangguan rasa nyaman, interaksi sosial, dan kepercayaan diri. Gangguan ketiga atau gangguan yang menonjol pada fisik seseorang yaitu tanda kemerahan pada kulit yang akan ditemukan pada jari-jari, kaki, leher, bahu, bawah ketiak, bahkan daerah genital. Gambaran skabies terlihat seperti kemerahan disertai dengan benjolan yang berukuran kecil (Tarwoto dan Wartonah, 2010).

Faktor risiko yang menyebabkan skabies antara lain rendahnya tingkat ekonomi, higienisitas yang buruk, hunian padat, perilaku seksual, tingkat pengetahuan, usia dan kontak langsung maupun tidak langsung dengan penderita (Handoko, 2010). Faktor yang sangat berperan terhadap timbulnya penyakit skabies yaitu personal hygiene. Personal hygiene menentukan status kesehatan seseorang secara sadar. Cara menjaga kesehatan tersebut meliputi menjaga kebersihan kulit, kebiasaan mencuci tangan dan kuku, frekuensi mengganti pakaian, pemakian handuk yang tidak bersamaan dengan orang lain, dan frekuensi mengganti sprei tempat tidur (Rohmawati, 2010).

Kebersihan kulit individu yang buruk atau bermasalah akan mengakibatkan dampak fisik maupun psikososial. Kebersihan tangan dan kuku, karena Sebagian besar masyarakat menggunakan tangan untuk beraktifitas, makan dan lain sebagainya. Kebersihan pakaian perlu dijaga, dalam sehari pakaian yang berkeringat dan berlemak ini akan berbau busuk dan mengganggu sehingga perlu diganti. Infestasi tungau Sarcoptes scabiei selain kebiasaan jarang mengganti pakaian dengan pakaian bersih serta pinjam-meminjam pakaian. Pinjam-meminjam pakaian dapat mempermudah penularan skabies secara kontak tidak langsung. Dalam keadaan ini masalah kesehatan yang akan muncul adalah pada kulit karena tubuh dalam keadaan lembab. Untuk itu perlu mengganti pakaian yang bersih setiap hari (Menaldi, 2015). Sanitasi Total Berbasis Masyarakat (STBM) memiliki lima pilar yaitu stop buang air besarsembarangan, cuci tangan pakai sabun,pengelolaan air minum dan makanan rumah tangga, pengamanan sampah rumah tangga, danpengamanan limbah cair rumah tangga (Surya, 2019). Penularan skabies yang utama adalah kontak langsung dan tidak langsung. Penyakit skabies dapat ditularkan melalui kontak tidak langsung seperti handuk, perlengkapan tidur, dan sprei. Berdasarkan penelitian menunjukkan 44 orang $(62,9 \%)$ terkena skabies dan ada hubungan antara 
kebiasaan pemakaian alat mandi secara bergantian, dan kebiasaan tidur bersamaan. Selain kebiasaan tidur bersamaan, kondisi kamar tidur meliputi suhu dan kelembaban ruangan juga dapat berperan dalam berkembang biaknya tungau Sarcoptes scabiei. Suhu yang lebih lembab dan panas akan menyebabkan aktivitas tungau akan menjadi lebih tinggi (Menaldi, 2015). Berdasarkan beberapa literatur yang didapatkan menunjukan bahwa ada hubungan antara personal hygiene dengan kejadian penyakit skabies. Hygiene perorangan merupakan faktor risiko terjadinya penyakit skabies (Sudiyanto, 2012) dan hygiene perorang juga merupakan salah satu usaha yang dapat mencegah kejadian skabies (Djuanda, 2007). Selain dilihat dari pengetahuan personal hygiene yang kurang dapat dilihat dari lingkungan yang kurang bersih, ketersediaan jumlah air yang kurang, serta sanitasi lingkungan yang kurang.

Menurut Adnani (2011), Pendidikan adalah sebagai upaya untuk mempengaruhi kelompok masyarakat sehingga melakukan yang diharapkan agar lebih baik. Sedangkan konseling adalah pertolongan dalam bentuk wawancara yang menuntut adanya komunikasi, interaksi, dan usaha bersama antara tenaga kesehatan dengan pasien untuk mencapai tujuan pemecahan masalah (Tyastuti, 2016). Berdasarkan penelitian pendidikan kesehatan yang dilakukan Masraini (2014), terapi personal hygiene penyakit kadangkadang mengalami kegagalan atau pengobatan tidak bisa mencapai optimal sehingga kasus skabies masih ada. Apabila tidak ada tindakan pencegahan untuk meningkatkan personal hygiene maka akan meningkatkan kejadian skabies dan pada akhirnya bisa menimbulkan endemik skabies. Dari uraian di atas menunjukkan bahwa promosi kesehatan tentang personal hygiene memberikan dampak positif pada peningkatan pengetahuan yang secara tidak langsung merubah tingkah laku atau tindakan dalam pemeliharaan diri yang baik, sehingga angka kejadian skabies dapat berkurang.

Berdasarkan pengumpulan data dari berbagai artikel maka didapatkan hasil, penatalaksanaan secara umum pada penderita yang sudah terkena penyakit skabies dianjurkan untuk menjaga kebersihan dan mandi secara teratur setiap hari bila perlu menggunakan sikat untuk menyikat badan. Sesudah mandi pakaian yang akan dipakai setidaknya di setrika. Semua pakaian, sprei, dan handuk yang telah digunakan harus dicuci secara teratur dan bila perlu direndam dengan air panas. semua perlengkapan rumah tangga seperti bangku, sofa, sprei, bantal, kasur, dan lainnya harus dibersihkan dan dijemur dibawah sinar matahari selama beberapa jam minimal 2 minggu sekali (Baker F, 2010). Selain itu menurut Sri Ganesh (2014), dapat dilihat bahwa sebagian besar seseorang mengalami perubahan pengetahuan mengenai personal hygiene setelah diberikan Pendidikan Kesehatan. Salah satu faktor yang mempengaruhi penerimaan seseorang terhadap suatu stimulus atau perubahan pengetahuan adalah dipengaruhi oleh faktor minat. Berdasarkan hasil dari berbagai artikel bahwasannya seseorang memiliki keinginan dan minat untuk mempelajari dan menerapkan metode personal hygiene yang baik dan benar yang akan diterapkan dikehidupan sehari-hari.

\section{Simpulan Dan Saran}

Terdapat hubungan signifikan antara personal hygiene dengan kejadian penyakit skabies. Semakin baik personal hygiene pada seseorang maka semakin mengurangi risiko penularan kontak langsung, maupun tidak langsung. Pemeliharaan personal hygiene berarti tindakan memelihara kebersihan dan kesehatan diri seseorang untuk kesejahteraan fisik dan psikisnya. Banyak manfaat yang dapat diperolah yaitu seperti memperbaiki, merawat kebersihan diri, dan mencegah penyakit. Cara menjaga kesehatan tersebut dapat dilakukan dengan menjaga kebersihan kulit, kebiasaan mencuci tangan dan 
kuku, frekuensi mengganti pakaian, pemakaian handuk yang tidak bersamaan dengan orang lain, dan frekuensi mengganti sprei tempat tidur.

\section{Daftar Rujukan}

Adnani, H. (2011). Ilmu Kesehatan Masyarakat. Nuha Medika. Jogyakarta.

Alimul, H. A. (2009). Kebutuhan Dasar Manusia Aplikasi Konsep dan Proses Perawatan. Jakarta : Salemba Medika.

Andayani, L. (2005). Perilaku Santri Dalam Upaya Pencegahan Penyakit Skabies di Pondok Pesantren Ulumu Qur'an stabat. Fakultas Kesehatan Masyarakat : Universitas Sumatra Utara, Medan.

Ariza, L., B, Walter., C, Worth., Brockman., Weber, M.L., \& H. Feldmeier. (2013). Investigation of Scabies Outbreak in Kindergarten in Costance Germany. Eur J. Clin Microbial Infect Dis (DOI). 10: 1007-96.

Audhah, N. A., Umniyati, S. R., \& Siswati, A. S. (2012). Faktor Resiko Skabies Pada Siswa Pondok Pesantren. Jurnal Buski. 4(1).

Badri, M. (2008). Hygiene Perseorangan Santri Pondok Pesantren Wali Songo Ngabar Ponorogo. Media Penelitian dan Pengembangan Kesehatan. Vol 17, No 2, Hal. 2.

Baker, F. (2010). Scabies Management. Paediatr Child Health. 6:775-7.

Bakri, A., Irwandy, F., \& Linggi, E. (2020). Pengaruh Pendidikan Kesehatan Tentang Perawatan Pasien Stroke Di Rumah Terhadap Tingkat Pengetahuan Keluarga. Jurnal Ilmiah Kesehatan Sandi Husada, 11(1), 372-378.

Departemen Kesehatan RI. (2008). Profil Kesehatan Indonesia 2007. Jakarta : Depkes RI Jakarta.

Departemen Kesehatan RI. (2012). Survei Kesehatan Dasar Indonesia. Jakarta : Kementerian Kesehatan Republik Indonesia.

Desmawati. (2015). Hubungan Personal Hygiene dan Sanitasi Lingkungan dengan Kejadian Scabies Di Pondok Pesantren Al-Kautsar Pekanbaru. Vol. 2, No. 1.

Djuanda, A. (2007). Ilmu Penyakit Kulit dan Kelamin Edisi Keempat. Cetakan Ketiga. Jakarta : Fakultas Kedokteran Universitas Indonesia.

Frenki. (2011). Hubungan Personal Hygiene Santri Dengan Kejadian Penyakit Kulit Infeksi Scabies dan Tinjauan Sanitasi Lingkungan Pondok Pesantren Darel Hikmah Kota Pekanbaru Tahun 2011. Fakultas Kesehatan Masyarakat. Skripsi: Universitas Sumatra Utara, Medan.

Handoko, R. (2010). Skabies dalam Ilmu Penyakit Kulit dan Kelamin (Edisi Keenam). 122 125. Jakarta : Badan Penerbit FK UI.

Heukelbach, J., \& Feldmeier, H. (2006). Scabies, Lancet. 367 : 1767 - 1774.

Mansyur, M., Wibowo, A., Maria, A., Munandar., Abdillah, A., \& Ramadora, A. (2007). Pendekatan Kedokteran Keluarga pada Penatalaksanaan Skabies Anak Usia PraSekolah. Majalah Kedokteran Indonesia. Vol. 57 No. $2: 63$ - 67.

Menaldi, S. L. S., Bramono, K., \& Indriatmi, W. (2015). Ilmu Penyakit Kulit dan Kelamin. Edisi ke-7. Jakarta: Fakultas Kedokteran Universitas Indonesia.

Murtiastutik, D. (2009). Atlas HIV\&AIDS dengan Kelainan Kulit. Fakultas Kedokteran Universitas Airlangga Rumah Sakit Umum Dr. Soetomo Surabaya: Airlangga University Press.

Rakhmawati, D. (2012). Laporan Kasus: Crusted Scabies. Pertemuan Ilmiah Tahunan XII PERDOSKI. Solo.

Rohmawati. (2010). Beberapa Faktor yang Berhubungan dengan Kejadian Skabies di Pondok Pesantren Nurul Hikmah Jatisawit Bumiayu Brebes. Skripsi : UNDIP Semarang. 
Sa'adatin, M., Wardani, RS., \& Ismail, TS. (2015). Hubungan hygiene perorangan, sanitasi lingkungan dan Riwayat kontak dengan kejadian scabies (skripsi). Fakultas Kesehatan Masyarakat Universitas Muhammadiyah.

Sudiyanto. (2012). Hubungan Personal Hygiene dan Sanitasi Lingkungan dengan Kejadian Skabies di Wilayah Kerja Puskesmas Lingkar Timur kota Bengkulu (tesis). Bengkulu: Stikes Dehasen.

Surya, J. (2019). Sanitasi Total Berbasis Masyarakat (STBM Dengan Diare Pada Balita. Jurnal Ilmiah Kesehatan Sandi Husada, 10(2), 281-284.

Sri G. A., Rose, D. M., \& Lipoeto, N. I. (2014). Hubungan Tingkat Pengetahuan dan Sikap dengan Tindakan Pencegahan Penyakit pada wanita di Kelurahan Jati. Fakultas Kedokteran Universitas Andalas.

Tarwoto., \& Wartonah. (2010). Kebutuhan Dasar Manusia dan Proses Keperawatan. 4th ed. Jakarta : Salemba Medika.

Tyastuti, Siti., Wahyuningsi., \& Henny. (2016). Asuhan Kebidanan Kehamilan. Modul Kebidanan. Jakarta : Kementrian Kesehatan RI.

Wijayanti, Y. (2008). Hubungan Sanitasi Lingkungan dan Hygiene Perorangan dengan Penyakit Skabies di Desa Genting Kec. Jambu Kab. Semarang tahun 2006. Jurnal KEMAS Vol. 3 No. 2. 